\title{
O design na sociedade líquida: reflexões sobre o processo criativo e o papel social do design(er).
}

\author{
Polyanna Astrath Costa ${ }^{1}$;
}

Fernanda Martins Ferreira de Araujo²;

resumo:

O conceito de modernidade líquida, teorizado pelo filosofo Zygmunt Bauman (2014), apresenta uma construção social embasada no individualismo e em pseudo-aparências ao identificar uma liquidez das relações sujeito-mundo. Dentro do cenário contemporâneo, tais relações são reafirmadas em utopias hiperconsumidoras vivenciadas na fetichização de posse de bens materiais, compostas em um contexto capitalista industrial (ADORNO e HORKHEIMER, 2009). Em contrapartida, um projeto de Design Social (PAZMINO, 2007) se baseia em criação de produtos e/ou serviços com intuito de viabilizar práticas sociais sob às reais necessidades de grupos marginalizados no âmbito sociocultural e econômico. 0 presente artigo propõe uma breve reflexão crítica sobre o design na sociedade líquida, na mesma medida em que apresenta questionamentos sobre produção industrial e o papel social do design(er) a partir de um cotejamento de trabalhos realizados na área.

palavras-chave:

modernidade líquida; hiperconsumismo; design; papel social do design; processo criativo.

\footnotetext{
${ }^{1}$ http://lattes.cnpq.br/2343270374480449

${ }^{2}$ http://lattes.cnpq.br/4977483448970554
} 


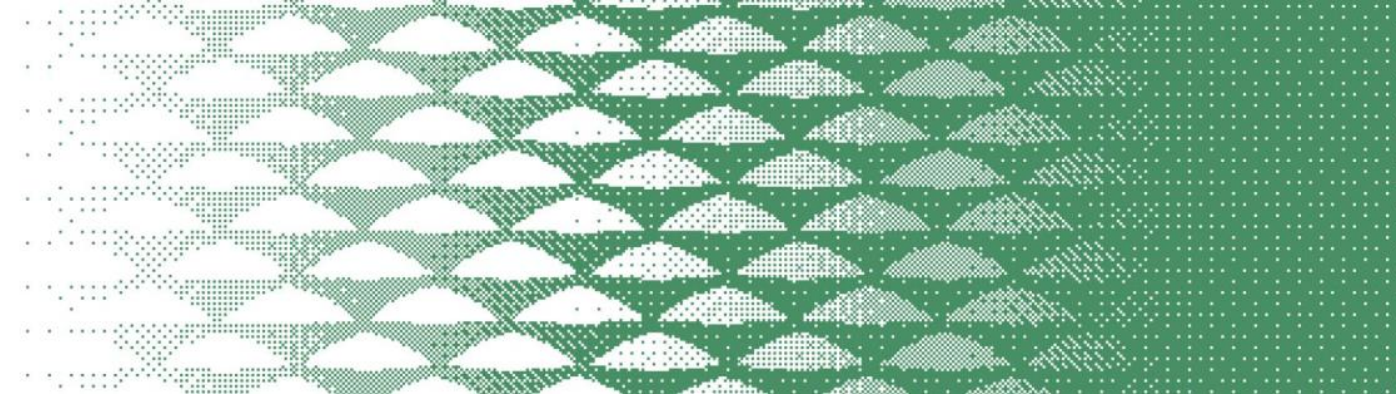

\section{Introdução}

A cultura contemporânea, tal como aponta Theodor W. Adorno e Max Horkheimer (2009), caracterizase por uma produção da semelhança que é constituída dentro de um sistema regrado por convenções estéticas demarcadas por uma indústria cultural. A indústria cultural preza por uma estandardização e produção serial de seus produtos e mídias em função do capital econômico, implicando uma "atrofia da imaginação e da espontaneidade" (ADORNO e HORKHEIMER, 2009, p.10) tanto do consumidor, quanto do artista-produtor.

Ao ser apresentada por meio de óticas neoliberais capitalistas, percebemos que a obra de arte, enquanto processo criativo e produto, vende a utopia unidimensional da realidade ao ser sistematicamente promovida por meios de comunicação de massa (rádio, televisão, cinema, revistas, etc.), reduzindo-a à representações caracterizadas por clichês, universalização e estereótipos, conceitos que reprimem e sufocam aqueles que se apresentam a margens das representações. A marginalização de sujeitos e culturas é explorada ao venderem uma solidariedade improvisada (ADORNO e HORKHEIMER, 2009, p.30), um triunfo falacioso para vida da bourgeoisie ao abandonar o seu poder coletivo, fazendo com que este se comporte a partir do pensamento individualista. O indivíduo ilusório é apenas tolerado "à medida que sua identidade sem reservas com universo permanece fora de contestação" (ADORNO e HORKHEIMER, 2009, p. 33), reduzindo-se a pontos de identificação imediatista expostos por produções seriadas que se apresentam naturalizadas, e não como construções sociais.

No mesmo movimento, o filósofo Zygmunt Bauman (2014) discorre que a sociedade moderna atual se pauta em uma liquidez de pensamentos e teorias devido a sua não-evidência no âmbito sociopolítico. A sociedade líquida tem como base tarefas individuais a nível micro do convívio social, resultando em uma "versão individualizada e privatizada da modernidade" (BAUMAN, 2014, p.22), a qual se apresenta como efêmera. Essa individualização é o resultado do tornar-se indivíduo, isto é, a autodeterminação compulsiva e obrigatória de uma posição heterônoma social (ibid., p.53) que se manifesta em uma lógica de consumo.

Com base nesta discussão, pontuamos que o Design é capaz de se tornar uma ferramenta de propagação do ideal neoliberal ao marginalizar as necessidades da atuação social e coletiva do Design, enquanto produto e processo, no macrossocial. Assim, o presente artigo busca, através de uma redação analítica, traçar um paralelo entre o papel do designer na sociedade de consumo e o papel social do design, expondo exemplos de como o design pode atuar em contramão ao ideal neoliberal, libertandose do hiperconsumo.

\section{0 design(er) na sociedade de consumo}

O campo do Design, articulado com a sociedade de consumo, utiliza estratégias semióticas a fim de atribuir valores simbólicos a determinados produtos. Essas estratégias, analisadas por Alécio Rossi Filho (2018), estão correlacionadas ao marketing e à comunicação para construir uma imagem pública de alto valor material, assim se constituindo como instituições. O papel dos designers, sob esta ótica hiperconsumista, é aplicar a semiótica com o objetivo de tornar um produto e/ou serviço "diferenciado" dos seus similares no mercado, vendendo hábitos de consumo que reforça o pertencimento em grupos semelhantes (ROSSI FILHO, 2018, p.53).

Outro papel do design(er) na sociedade hiperconsumidora é desenhar e construir a aparência de um "futuro melhor (utopia) com melhor qualidade de vida para todos" (ROSSI FILHO, 2018, p. 47), resultando na venda da ideia de um fluxo imaterial, isto é, o prazer da vida. O processo de consumo simbólico enfraquece diferenças e a pluralidades identitárias ao torná-las semelhantes, mesmo dentro da 


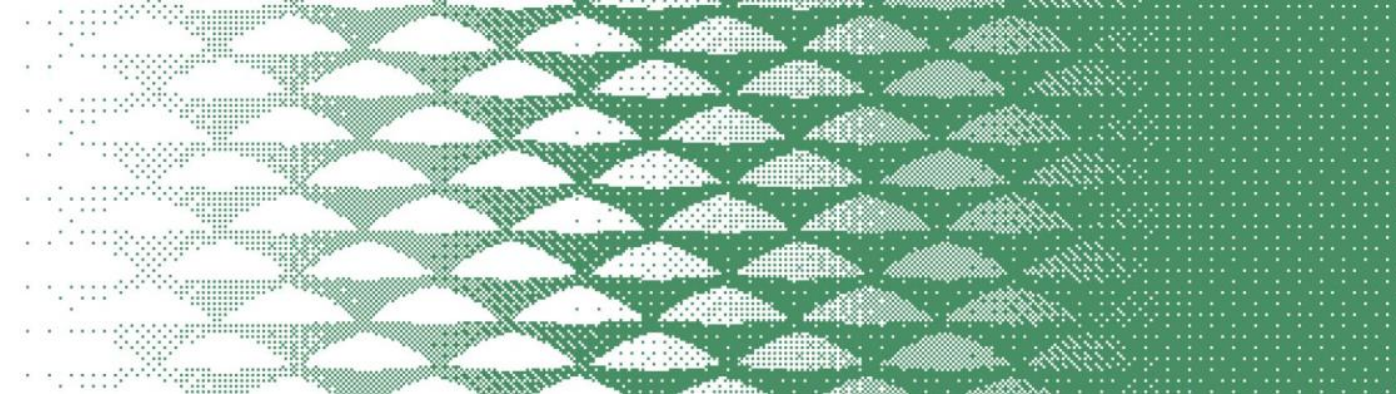

construção individualista líquida. Vende-se uma ideia de representação e simulação de um estilo de vida belo e bem-sucedido, em que o sujeito desaparece do centro, dando espaço a uma fetichização utópica da realidade. Assim, os aspectos culturais desta sociedade constroem "desejos de consumo [que] se mesclam também ao desejo de ser visto, reconhecido, desejado" (ROSSI FILHO, 2018, p. 189, adaptado).

A cultura líquida, para Bruna Dória (2019), molda-se à "liberdade individual de escolha e à responsabilidade, igualmente individual, por essa escolha” (DÓRIA, 2019, p. 4), guiadas por uma homogeneização cultural que pauta um desejo por capital cultural e econômico. Há uma aparência de liberdade criativa que permite a transição e escolha do sujeito de uma identidade pessoal. Contudo, o caráter identitário resulta no sujeito fragmentado e multicultural ao tornar as fronteiras do espaço geográfico subjetivo de cada indivíduo.

Nesse sentido, podemos pontuar que o design(er) é ao mesmo tempo guiado por forças internas (criatividade, subjetividade, interpretação) e por forças externas (contexto sociocultural, econômico, demandas capitalistas), tornando-o um processo comercial de uma dualidade. Parafraseando Rossi Filho (2018, p. 189), a criação do design é sempre vinculada ao seu contexto de produção e recepção, sendo o resultado do repertório do criador e uma resposta a um questionamento interno/externo.

No entanto, ao correlacionarmos essa identidade líquida a utopia do fetiche de posse material, o questionamento que nos apresenta (mas não se busca uma resposta) é: até que ponto nossa subjetividade é individual e não um constructo social? Com base nos estudos do crítico Peter Dormer (1995), o consumismo dá ao designer oportunidades "criativas" (isto é, a ilusão do ato criativo) ao colocá-lo como uma máquina produtora dentro de uma macroindústria, sendo necessário uma constante (re)inovação de bens matérias de grande e rápida escala. Devido a uma valorização efêmera ocidental, compreendemos que a espiral do consumo, que antes era dirigida por um prazer material, direcionou-se à "poluição, ao desperdício e à crise ambiental" (DORMER, 1995, p.38).

A partir dessas diretrizes, o papel dessas produções vão além do prazer estético e da criação capitalista, devido a necessidade de se direcionar, reduzir e solucionar problemas ocasionados por produções anteriores em concordâncias com pautas dos contextos sociopolíticos de recepção, como exemplo, a popularização de estudos sobre as estratégias de design para sustentabilidade, que desde os anos 60 se apresentam como uma solução para os impactos negativos da produção e consumo em massa (CESCHIN \& GAZIULUSOY, 2020).

Em conformidade com Jéssica Dalcin da Silva (2019), entendemos que o design(er) busca solucionar problemas intrínsecos à demanda, devendo ser "entendido como a capacidade presente em qualquer ser humano de transformações à sua condição vigente, por meio de condutas antecipatórias" (SILVA, 2019, p. 10). Os limites entre design e arte, tido nesse trabalho como processo criativo, são previstos por meio da mediação do designer "por meio da práxis [...], o designer tem a oportunidade de exercer uma filosofia de vida que dá materialidade ao seu pensar" (SILVA, 2019, p. 12).

$\mathrm{O}$ ato de fazer design é também o ato de se projetar como referência a outros através das problemáticas supracitadas. Nesse sentido, a designer "objetiva permear situações existentes para, ao alterá-las e construir situações preferidas, criar mudança" (SILVA, 2019, p. 15), compreendendo as necessidades da demanda social vigente de seu contexto de produção e recepção. A visão da autora se caracteriza por um decolonialismo teórico ocidental, em que se projeta uma ação dialógica entre estados de equidade, isto é, por colaborações entre partes que legitimam as relações e práticas sociais com um trabalho social e ético. 


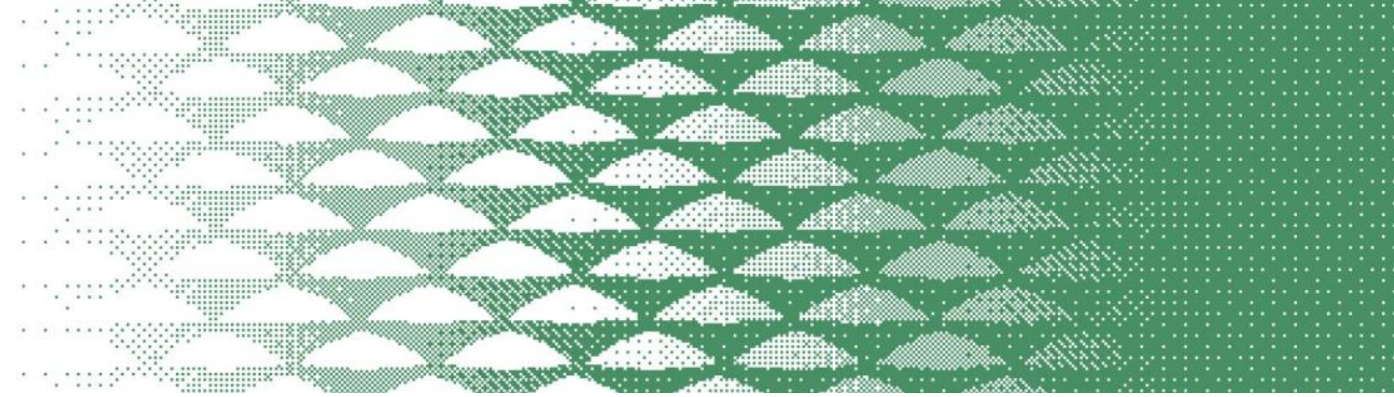

\section{O Design Social e o papel social do design(er)}

O Design social, segundo Ana Verónica Pazmino (2007), é um conceito que abrange o desenvolvimento de produtos sob as reais necessidades de grupos marginalizados no âmbito sociocultural e econômico, ou que apresentam necessidades específicas em relação à idade, saúde ou inaptidão. Essa área do Design atua em áreas que são indiferentes à indústria capitalista ao ter como objetivo soluções que auxiliem no melhoramento da qualidade de vida, renda e inclusão social do público alvo. Acreditamos que as ações que corroborem com esse conceito permitem que o designer assuma seu papel social, e ao assumir esse papel, o designer consegue projetar e materializar ações que auxiliem os grupos marginalizados na sociedade hiperconsumidora.

Com base nos estudos de Rafael Cardoso (2012, apud CURI, 2018, p. 24), o papel social do designer é construir pontes que desfragmentam os saberes, isto é, permitir as multidisciplinaridades no processo de construção criativa. A ética profissional é uma peça-chave para a exerção desse papel, pois acomoda os interesses entre cliente-usuário, bem como se deleita em sua responsabilidade social a fim de demonstrar as identidades plurais, que cada vez mais são cobradas por usuários devido a uma nãorepresentação de assuntos e corpos marginalizados nas mídias.

Para Maria Célia dos Santos (2016), o designer que reflete sobre sua responsabilidade social deve permitir o reflexo da sua participação pública na sua prática produtiva, preocupando-se com questões que descentralizem os meios de produção capitalistas ao não se colocar enquanto "agente desresponsabilizador" (SANTOS, 2016, p. 16). O resultado dessa autorreflexão são projetos que se dedicam e se responsabilizam ao melhoramento da qualidade de vida desses grupos marginalizados, bem como elencam questões e pautas referentes a problemáticas vistas nos sistemas de gênero, raça e classe.

A pesquisadora Clara Klein Curi (2018), pontua que (re)afirmar as categorias sociais como artificiais é contribuir para a manutenção de uma estrutura política (CURI, 2018, p. 23). Seu posicionamento é observado em seu projeto, denominado Recort, que expõem conteúdos produzidos colaborativamente sobre tópicos silenciados, a exemplo da temática "objetificação da mulher" (Figura 1). Considerando o conceito de Design Social discutido por Pazmino (2007), observamos que o trabalho desenvolvido por Curi (2018) tinha como objetivo dar local de fala aos grupos marginalizados, no caso as Mulheres, para exporem as problemáticas e silenciamentos recorrentes em seus contextos, permitindo uma representação plural e autêntica dessas identidades. 

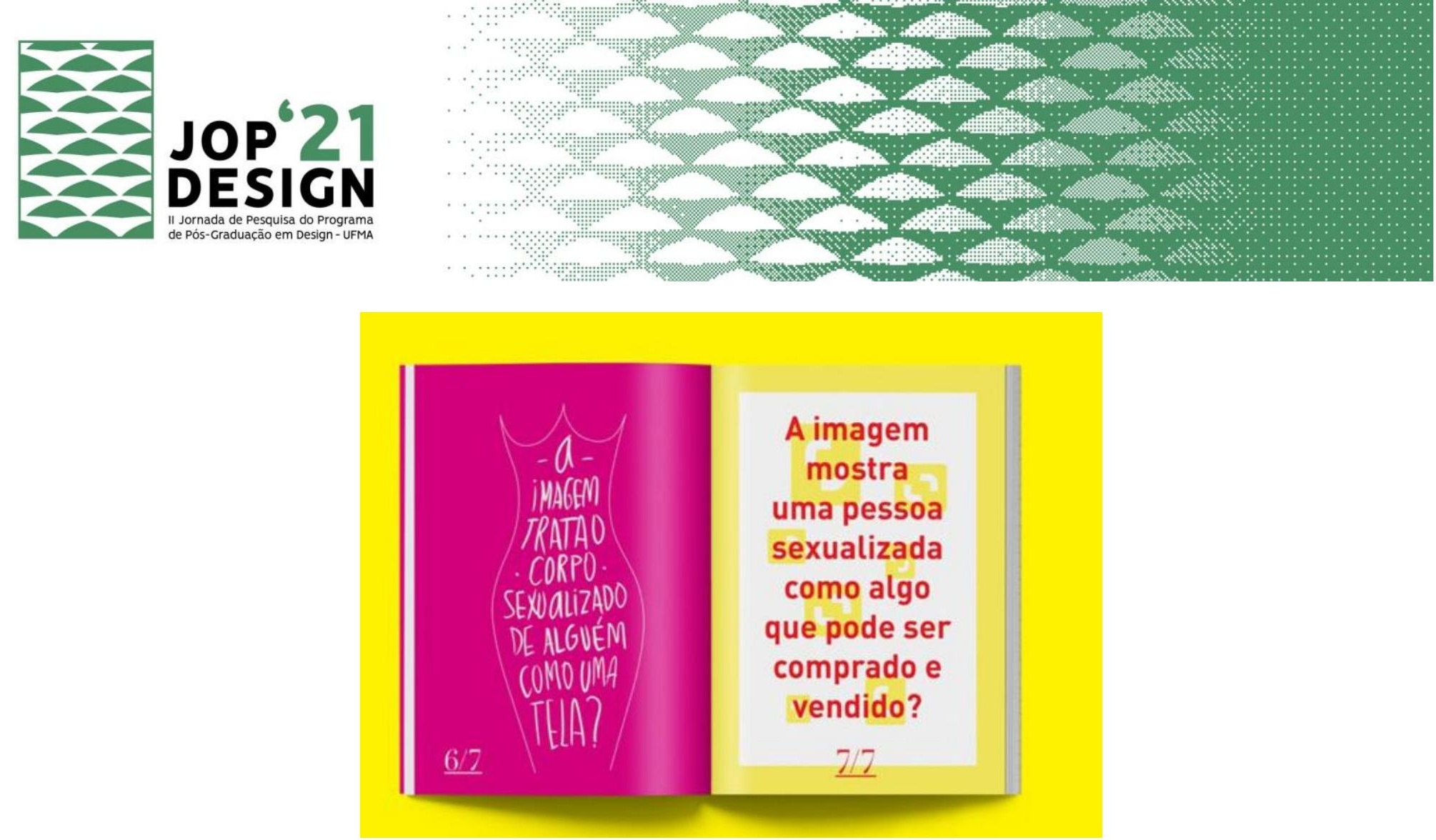

Figura 1 - A objetificação da mulher, segundo Caroline Heldman. Fonte: CURI, 2018, p. 81.

Fabio Lopez (2007), designer carioca, criou uma versão do tradicional jogo de estratégia WAR chamado "War in Rio" (Figura 2) que busca dar visibilidade, de forma irreverente, sobre a guerra as drogas presentes no contexto sociocultural do Rio de Janeiro. Por meio do jogo e da gamificação, o designer objetivou demonstrar a realidade daqueles que vivem em meio a "impunidade que banaliza a violência que a injustiça social patrocina - e a passividade mantém tudo em seu lugar" e assim levar a discussão sobre a capital. Desta forma, por meio da prática social do design, é possível abordar pautas sociais importantes em contextos inusitados, dando voz àqueles que estão à margem da sociedade.

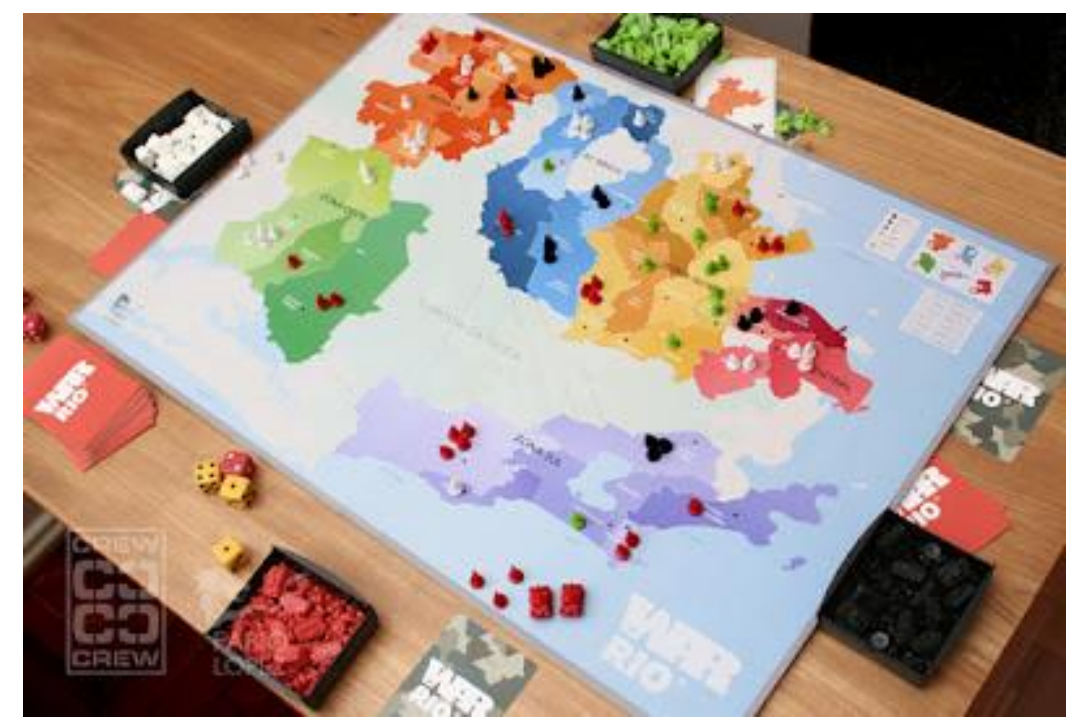

Figura 2 - War in Rio

Fonte: Fabio Lopez, disponível em http://jogowarinrio.blogspot.com.br/

Pensando na prática que visa o melhoramento dos corpos marginalizados, o projeto "Maria" (Figura 3), conceitualizado por Rafaella Gonçalves (2019), objetiva a produção de absorventes sustentáveis para mulheres em situação de rua na cidade de Curitiba, Paraná. O projeto de Gonçalvez (2019) afirma que o "absorvente interno poderá ser personalizado em diversos tamanhos, dependendo 


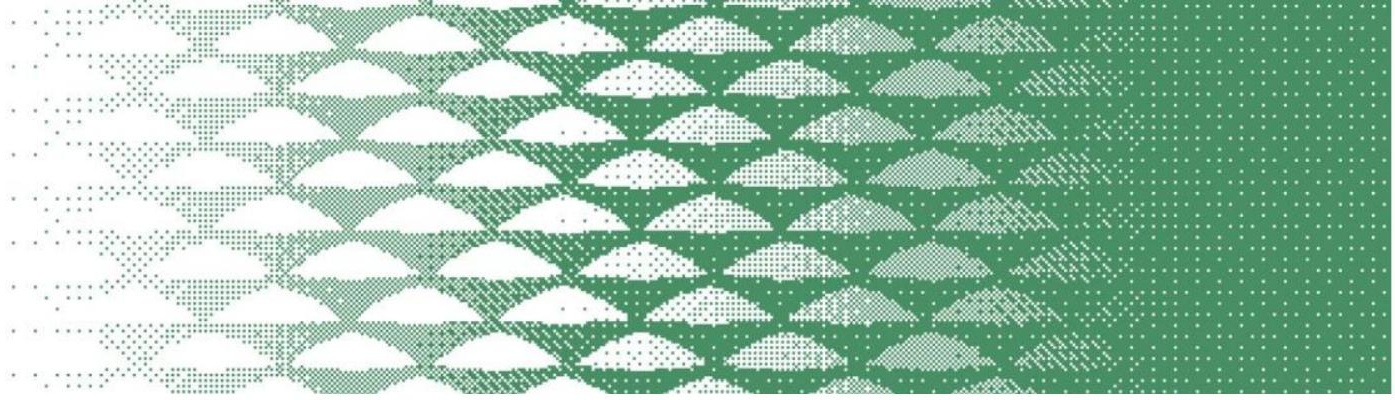

da necessidade e do fluxo de cada mulher". Apesar da importância do projeto, esse ainda está em fase conceitual e não há um estudo de caso com as usuárias.

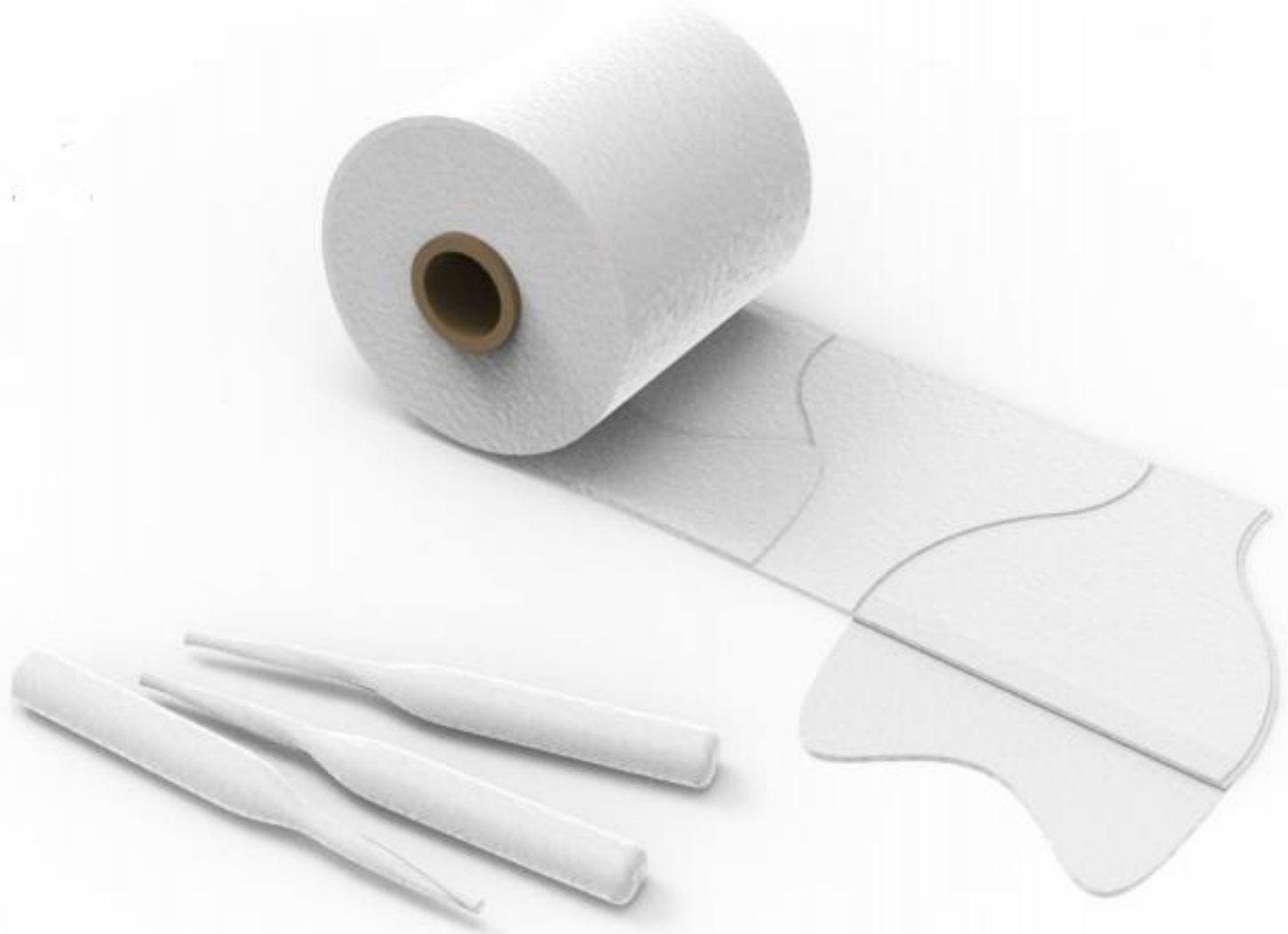

Figura 3 - Absorvente Maria

Fonte: Rafaella Gonçalves (2019)

Apesar dos exemplos possuírem objetivos e públicos-alvo distintos, percebe-se em seu processo criativo se prezou por uma coletividade e a pluralidade de ações, condizentes com a discussão proposta por Pazmino (2007) e Santos (2016). Em nenhum dos projetos ocorreu o que Rossi Filho (2018) pontuou como a fetichização de uma utopia capitalista, ou a venda de um objeto de luxo que demarcasse um não-pertencimento, demonstrando que as possibilidades do campo de design vão além da criação de produtos que seguem a ótica capitalista, pelo contrário, tais exemplos reitera a preocupação social e a descentralização no indivíduo como único.

\section{Considerações Finais}

Considerando as reflexões apresentadas, a crítica que apresentamos a sociedade hiperconsumidora e do alto consumo é devido ao possuírem seus modelos não condizentes com identidades plurais, ao mesmo tempo em que marginaliza e silencia problemáticas que não são do interesse capital, resultando no apagamento da não-padronização neoliberal. Acreditamos que a sociedade líquida capitalista, portanto, impede a diversidade de olhares em suas instituições na medida em que busca vender a hegemonia cultural como algo a ser alcançável mesmo diante das impossibilidades socioeconômicas. 
Corroborando-nos em ideias pós-modernas, que preveem a celebração da heterogeneidade e a desconstrução de preceitos neoliberais, podemos reafirmar uma nova aura, uma nova essência do design enquanto arte e ato criativo ao atribuir uma ressignificação de seu processo criador, redirecionando para seu papel social. Acreditamos que o papel social, vinculado a área do Design, necessita de uma maior discussão, pois nos leva a pensar em soluções para cultura local que desestabiliza o sistema industrial massivo, além de auxiliar em práticas sociopolíticas coletivas que retornam lucro e produtos para a cultura local. O Design Social não é, portanto, uma perda da atuação criativa, mas sim a possiblidade criativa e comunitária de atuação do design em prol de um bem comum.

Design in a liquid society: reflections on the creative process

Abstract: The concept of Liquid Modernity, theorized by the philosopher Zygmunt Bauman (2014), presents a social construction based on individualism and pseudo-appearances by identifying liquidity of subject-world relations. Within the contemporary scenario, these relations are reaffirmed in hyperconsumption utopias experienced in the fetishization of material goods' possession, composed in an industrial capitalist context (ADORNO and HORKHEIMER, 2009). On the other hand, a Social Design project (PAZMINO, 2007) is based on the creation of products and/or services with the purpose of enabling social practices under the real needs of marginalized groups in the socio-cultural and economic scope. This article proposes a brief critical reflection about design in a liquid society, as it presents questions about industrial production and the social role of design from a comparison of works done in the area.

Keywords: liquid modernity; hyper-consumerism; ethics; the social role of design; creative process.

\section{Referências bibliográficas}

ADORNO, Theodor W; HORKHEIMER, Max. O Iluminismo como mistificação das massas. In: ADORNO, T. W. Indústria Cultural e Sociedade. 5 ed. São Paulo: Paz e Terra, 2009.

BAUMAN, Zygmunt. Modernidade Líquida. Rio de Janeiro: Editora Zahar, 2014.

CESCHIN, Fabrizio; GAZIULUSOY, İdil. Design for sustainability: A multi-level framework from products to socio-technical systems. Oxon: Routledge, 2019.

CURI, Clara Klein. Vamos falar sobre ética no design?. 2018, 92 f. Monografia (Graduação em Comunicação Visual Design) - Escola de Belas Artes, Universidade Federal do Rio de Janeiro, 2018.

DORMER, Peter. Os significados do design moderno: A caminho do séc. XXI. Lisboa: Centro Português de Design, 1995.

DÓRIA, Bruna. Identidade Cultural na contemporaneidade: relações fluidas entre arte e design. In: IV Congresso Internacional Sobre Culturas. Anais..., Bahia, vol. 1, p.1-12, 2019. 
GONÇALVEZ, Rafaella. Maria, absorvente íntimo. 2019. Disponível em: <https://www.cbd.org.br/wpcontent/uploads/2019/09/RAFAELLA-DE-B.-MARIA-ABSORVENTE-\%C3\%8DNTIMO.pdf>. Acesso em: 05 ago. 2021.

LOPEZ, Fabio. War in Rio, o jogo. Website War in Rio, 2007. Disponível em: <http://jogowarinrio.blogspot.com.br>. Acesso em: 05 ago. 2021.

PAZMINO, Ana Verónica. Uma reflexão sobre design social, eco design e design sustentável.

Simpósio Brasileiro de Design Sustentável, v. 1, p. 1-4, 2007.

ROSSI FILHO, Alécio. Design, arte e consumo. 2018, 204 f. Tese (Doutorado em Design e Arquitetura) - Faculdade de Arquitetura e Urbanismo, Universidade de São Paulo, 2018.

SANTOS, Maria Cecília Loschiavo dos. Conectando ética e estética: Reflexões sobre o design. In: $12^{\circ}$ Congresso Brasileiro de Pesquisa e Desenvolvimento em Design. Anais... v. 9, n.2, p.9-13. São Paulo: Blucher, 2016.

DA SILVA, Jéssica Dalcin; STREHL, Jerônimo. Design(er) não soluciona problemas: uma crítica epistemológica contra-hegemônica. Revista Poliedro, Pelotas, v. 3, n. 3, p. 4-18, dez. 2019. 